\title{
A New ZVS LCL-Resonant Push-Pull DC-DC Converter Topology
}

\author{
Michael J. Ryan, William E. Brumsickle, Deepak M. Divan, Fellow, IEEE, and Robert D. Lorenz, Fellow, IEEE
}

\begin{abstract}
A new $L C L$ resonant dc-dc converter topology is presented in which the resonant $C L$ components are located after the output rectifier diodes. The push-pull converter topology is suitable for unregulated low-voltage to high-voltage power conversion, as in battery-powered systems, where input currents can exceed input voltages by an order of magnitude. The resonant circuit operates at twice the switching frequency, allowing for small resonant components. The MOSFET primary switches operate under zero-voltage switching (ZVS) conditions due to commutation of the transformer magnetizing current and the snubbing effect of the inherent drain-source capacitance. Output rectifier turn-off is effectively snubbed by the resonant capacitor. Laboratory tests show $93 \%$ efficiency at 12-V 160-A input, 235-V 1.8-kW output. Surge capability of up to $5 \mathrm{~kW}$ for $1 \mathrm{~s}$ has been tested. Circuit simulations and experimental results are presented and are shown to have excellent agreement with fundamental mode analysis.
\end{abstract}

Index Terms-DC-DC converter, push-pull topology, resonant converter, zero-voltage soft switching.

\section{INTRODUCTION}

A NEW LCL-resonant dc-dc converter topology suitable for unregulated low-voltage to high-voltage conversion is presented. The converter acts as a "dc transformer" in systems where power from a low-voltage source, typically batteries, must be converted to an unregulated, albeit stiff, higher intermediate voltage for use by a subsequent converter stage. In these systems, the limited energy storage capacity of the battery calls for very high efficiency in the dc-dc converter. For medium-power applications, input currents can exceed input voltages by an order of magnitude, thus presenting unique challenges for a high-efficiency design.

The basic push-pull topology used in this converter has the following advantages: 1) a single device voltage drop on the input side, where the source dc voltage is low (12-24

Paper IPCSD 98-39, presented at the 1997 Industry Applications Society Annual Meeting. New Orleans, LA, October 5-9, and approved for publication in the IEEE TRANSACTIONS ON INDUSTRY APPLICATIONS by the Industrial Power Converter Committee of the IEEE Industry Applications Society. Manuscript released for publication June 4, 1998.

M. J. Ryan was with the Department of Electrical and Computer Engineering, University of Wisconsin, Madison, WI 53706 USA. He is now with the Institute for Power Electronics and Electric Drives, RWTH-Aaachen, D-52066 Aaachen, Germany.

W. E. Brumsickle and R. D. Lorenz are with the Department of Electrical and Computer Engineering, University of Wisconsin, Madison, WI 53706 USA.

D. M. Divan is with Soft Switching Technologies Corporation, Middleton, WI 53562 USA, on leave from the Department of Electrical and Computer Engineering, University of Wisconsin, Madison, WI 53706 USA.

Publisher Item Identifier S 0093-9994(98)07221-1.
V) and current may be high ( $>150$ A); 2) nearly continuous power flow, keeping the peak currents down to a reasonable level; and 3) zero-voltage turn-on of switching devices due to commutation of the transformer magnetizing current [1]. With paralleled MOSFET switches, zero-voltage turn-off is provided by the inherent drain-source capacitance of the switches [7].

In contrast to the $L C L$-resonant converter topologies presented previously in the literature [4]-[6], the $L-C-L$ resonant topology presented in this paper is unique in that the $C-L$ resonant components are located after the output stage rectifiers. Fig. 1 depicts the converter topology.

The $L C L$-resonant output stage provides for a reducedcurrent turn-off of the primary switches, thus keeping the trapped primary leakage energy to a minimum. In effect, the $L C L$ circuit acts as a "tuned" output filter for the converter. In addition, the resonant capacitor effectively snubs the rectifier diodes' reverse-recovery transients. A unique coaxially wound transformer [2] provides extremely low interprimary leakage inductance and resistance. With inherently thermally stable resonant properties, a fixed-frequency, fixed-duty-cycle openloop control is all that is required for converter operation. In tests, the converter has exhibited an input current-frequency product of $4.2 \mathrm{~A} \cdot \mathrm{MHz}$.

The following sections cover converter topology and operation, computer simulations, experimental results, and conclusions.

\section{LCL-RESONANT Push-Pull CONVERTER TOPOLOGY}

The switches $S_{1}$ and $S_{2}$ in Fig. 1 each represent several ultralow $R_{d s \text {,on }}$ MOSFET's in parallel. These devices share current well and provide high-efficiency switching with excellent surge capability. Fig. 2 depicts the modeling of the coaxial transformer used in the converter prototype.

The coaxially wound transformer has a two-turn centertapped primary winding (one turn each). Due to its design, the primary-side leakage inductance is extremely low and, so, all leakage inductance can be considered to be limited to the secondary side of the transformer $\left(L_{l}\right)$. The leakage field is confined to the internal space surrounding the secondary turns, and any flux in the ferrite cores is, by structure, mutual flux [3]. Since the leakage flux of the transformer does not pass through the transformer core, there is no saturation of the leakage inductance. Thus, the $L C L$ resonance point will not change with transformer loading.

The final $C-L$ components (located after the full-wave rectifier) resonate with the leakage of the transformer at 


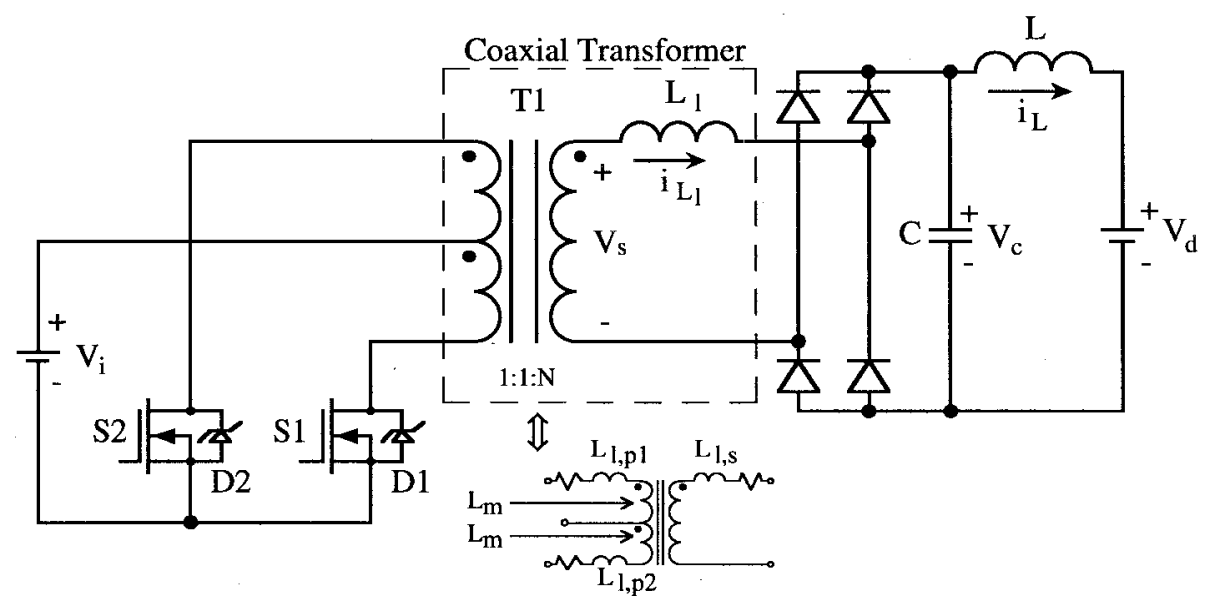

Fig. 1. $L C L$ resonant push-pull dc-dc converter topology.

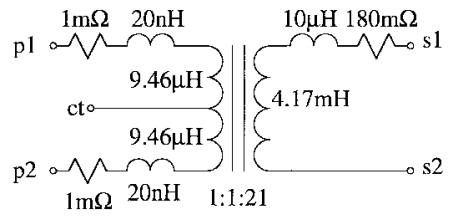

(a)

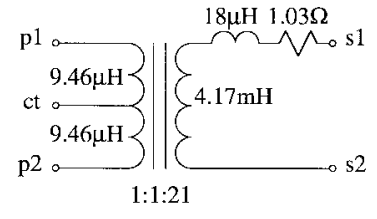

(b)
Fig. 2. Coaxial transformer models. (a) Full model. (b) Lumped secondary.

twice the switching frequency of $S_{1}$ and $S_{2}$. By using a good quality (highly stable) capacitor for $C$ and an aircore inductor for $L$, the $L C L$ resonant frequency will remain constant over the entire range of converter loading. With high-frequency switching $(25-50 \mathrm{kHz})$, the transformer and resonant components are kept relatively small.

Although the primary-side leakage is assumed zero for the following fundamental mode analysis, some energy is actually trapped in this leakage inductance (equal to $0.5 I^{2} L$ ) and must be dissipated by avalanching the body diodes of the MOSFET's. This trapped energy is significant, due to the high primary current of the converter, and will be addressed in a later section. The avalanche action of the MOSFET body diodes can be neglected for the purposes of understanding the basic operation of the resonant circuit.

\section{A. Fundamental Modes of Operation}

In general, the converter operates in conventional push-pull fashion, with the switches each running at 50\% duty cycle, $180^{\circ}$ out of phase. The net effect is a square-wave voltage impressed across the primary of the transformer $\pm V_{i}$. During switch commutation, the magnetizing current of the transformer will flow through the body diodes of the MOSFET's, leading to a zero-voltage turn-on. The output stage is a conventional full-wave rectifier, with the exception of the additional $C$ and $L$ resonant components, which along with the leakage of the transformer form the $L C L$-resonant circuit.

The converter has four fundamental modes of operation, as depicted in Fig. 3(a)-(d), where damping has been ignored. Note that Mode 1 begins when $S_{2}$ turns off and $S_{1}$ turns on (zero deadtime assumed). Equivalent circuit models for each mode are also shown in the figures, in which $V_{s}=N V_{i}$, where $N$ is the transformer turns ratio.

In normal operation, Modes 1 and 3 represent brief switching transitions wherein the transformer magnetizing current is commutated. The majority of the power flow occurs in Modes 2 and 4.

\section{B. Mode Equations}

For each of the four modes in Fig. 3, closed-form equations for circuit operation are found; damping has been ignored. These equations are listed below. Initial inductor currents and capacitor voltage at the start of each mode (when the input MOSFET's and/or output rectifiers switch) are designated as $I_{L 0}, I_{L_{1} 0}$, and $V_{C 0}$, respectively. These initial conditions are found from the end values of the previous mode. Note that the terms $V_{0}$ and $I_{0}$ are redefined for each mode.

$$
\begin{aligned}
\text { Mode } 1\left(S_{2} \rightarrow\right. & \text { Off, } \left.S_{1} \rightarrow \text { On, } i_{L_{l}}<0\right): \\
i_{L_{1}}(t)= & I_{0}+\left(I_{L_{1} 0}-I_{0}\right) \cos \left(\omega_{0} t\right) \\
& +\left(\frac{\left(V_{s}+V_{C 0}\right)}{Z_{4}}-\frac{\left(V_{s}+V_{d}\right)}{Z_{2}}\right) \sin \left(\omega_{0} t\right) \\
& +\frac{\left(V_{s}+V_{d}\right)}{Z_{2}}\left(\omega_{0} t\right) \\
I_{0}= & \left(\frac{L_{1} I_{L_{1} 0}-L I_{L 0}}{L^{\prime}}\right) \\
v_{C}(t)= & V_{0}+\left(V_{C 0}-V_{0}\right) \cos \left(\omega_{0} t\right) \\
& +\left(-I_{L_{1} 0}-I_{L 0}\right) Z_{3} \sin \left(\omega_{0} t\right) \\
V_{0}= & \left(\frac{L_{1} V_{d}-L V_{s}}{L^{\prime}}\right) \\
i_{L}(t)= & -I_{0}+\left(I_{L 0}+I_{0}\right) \cos \left(\omega_{0} t\right) \\
& +\left(\frac{\left(V_{C 0}-V_{d}\right)}{Z_{1}}+\frac{\left(V_{s}+V_{d}\right)}{Z_{2}}\right) \sin \left(\omega_{0} t\right) \\
& -\frac{\left(V_{s}+V_{d}\right)}{Z_{2}}\left(\omega_{0} t\right) .
\end{aligned}
$$




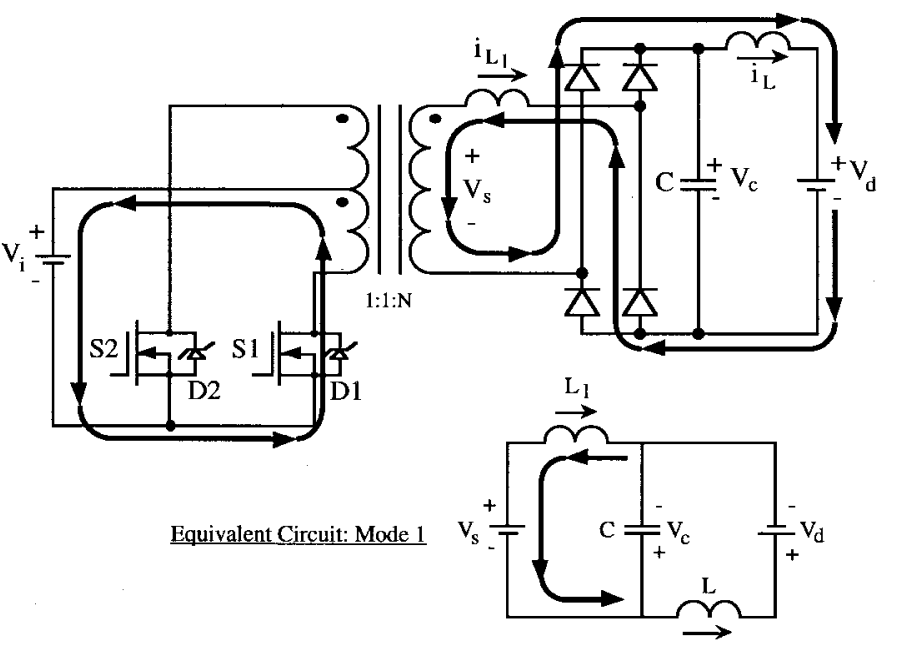

(a)

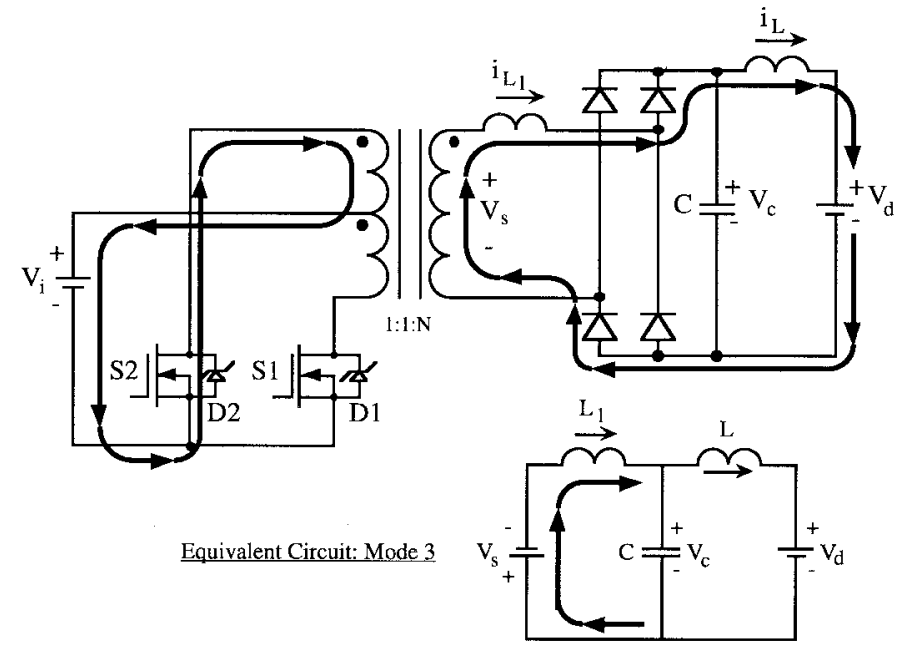

(c)

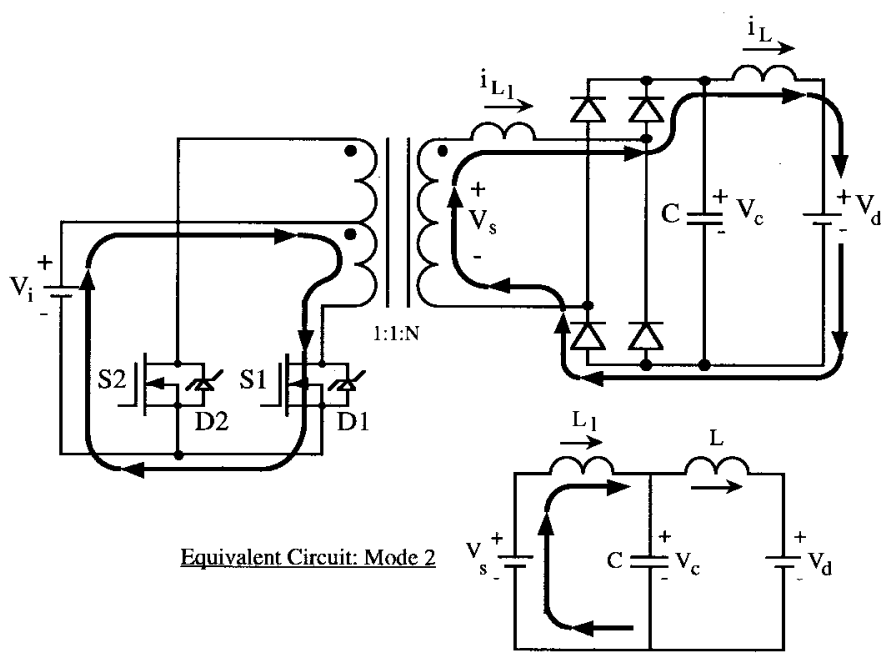

(b)

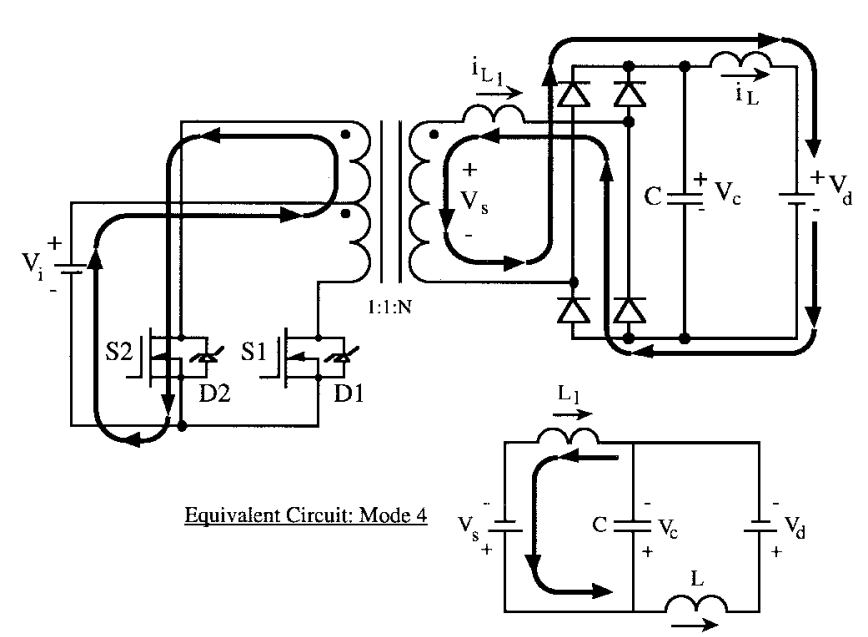

(d)

Fig. 3. (a) Mode 1: $S_{1} \rightarrow$ Off, $S_{1} \rightarrow$ On, $i_{L_{l}}<0$. (b) Mode 2: $S_{1}=$ On, $S_{2}=$ Off, $i_{L_{l}}>0$. (c) Mode $3: S_{1} \rightarrow$ Off, $S_{2} \rightarrow$ On, $i_{L_{l}}>0$. (d) Mode 4: $S_{2}=$ On, $S 1=$ Off, $i_{L_{l}}<0$.

$$
\begin{aligned}
\text { Mode } 2\left(S_{1}=\right. & \text { On, } \left.S 2=\text { Off, } i_{L l}>0\right): \\
i_{L_{1}}(t)= & I_{0}+\left(I_{L_{1} 0}-I_{0}\right) \cos \left(\omega_{0} t\right) \\
& +\left(\frac{\left(V_{s}-V_{C 0}\right)}{Z_{4}}-\frac{\left(V_{s}-V_{d}\right)}{Z_{2}}\right) \sin \left(\omega_{0} t\right) \\
& +\frac{\left(V_{s}-V_{d}\right)}{Z_{2}}\left(\omega_{0} t\right) \\
I_{0}= & \left(\frac{L I_{L 0}+L_{1} I_{L_{1} 0}}{L^{\prime}}\right) \\
v_{C}(t)= & V_{0}+\left(V_{C 0}-V_{0}\right) \cos \left(\omega_{0} t\right) \\
& +\left(I_{L_{1} 0}-I_{L 0}\right) Z_{3} \sin \left(\omega_{0} t\right) \\
V_{0}= & \left(\frac{L_{1} V_{d}+L V_{s}}{L^{\prime}}\right) \\
i_{L}(t)= & I_{0}+\left(I_{L 0}-I_{0}\right) \cos \left(\omega_{0} t\right) \\
& +\left(\frac{\left(V_{C 0}-V_{d}\right)}{Z_{1}}+\frac{\left(V_{s}-V_{d}\right)}{Z_{2}}\right) \sin \left(\omega_{0} t\right) \\
& -\frac{\left(V_{s}-V_{d}\right)}{Z_{2}}\left(\omega_{0} t\right) .
\end{aligned}
$$

Mode $3\left(S 1 \rightarrow\right.$ Off, $S_{2} \rightarrow$ On, $\left.i_{L l}>0\right)$ :

$$
\begin{aligned}
i_{L_{1}}(t)= & I_{0}+\left(I_{L_{1} 0}-I_{0}\right) \cos \left(\omega_{0} t\right) \\
& +\left(\frac{\left(-V_{s}-V_{C 0}\right)}{Z_{4}}-\frac{\left(V_{s}+V_{d}\right)}{Z_{2}}\right) \sin \left(\omega_{0} t\right) \\
& -\frac{\left(V_{s}+V_{d}\right)}{Z_{2}}\left(\omega_{0} t\right) \\
I_{0}= & \left(\frac{L_{1} I_{L_{1} 0}-L I_{L 0}}{L^{\prime}}\right) \\
v_{C}(t)= & V_{0}+\left(V_{C 0}-V_{0}\right) \cos \left(\omega_{0} t\right) \\
& +\left(I_{L_{1} 0}-I_{L 0}\right) Z_{3} \sin \left(\omega_{0} t\right) \\
V_{0}= & \left(\frac{L_{1} V_{d}-L V_{s}}{L^{\prime}}\right) \\
i_{L}(t)= & I_{0}+\left(I_{L 0}+I_{0}\right) \cos \left(\omega_{0} t\right) \\
& +\left(\frac{\left(V_{C 0}-V_{d}\right)}{Z_{1}}+\frac{\left(V_{s}+V_{d}\right)}{Z_{2}}\right) \sin \left(\omega_{0} t\right) \\
& -\frac{\left(V_{s}+V_{d}\right)}{Z_{2}}\left(\omega_{0} t\right) .
\end{aligned}
$$


Mode $4\left(S_{2}=\right.$ On, $S_{1}=$ Off, $\left.i_{L l}<0\right)$ :

$$
\begin{aligned}
i_{L_{1}}(t)= & I_{0}+\left(I_{L_{1} 0}-I_{0}\right) \cos \left(\omega_{0} t\right) \\
& +\left(\frac{\left(V_{C 0}-V_{s}\right)}{Z_{4}}-\frac{\left(V_{d}-V_{s}\right)}{Z_{2}}\right) \sin \left(\omega_{0} t\right) \\
& +\frac{\left(V_{d}-V_{s}\right)}{Z_{2}}\left(\omega_{0} t\right) \\
I_{0}= & \left(\frac{L_{1} I_{L_{1} 0}+L I_{L 0}}{L^{\prime}}\right) \\
v_{C}(t)= & V_{0}+\left(V_{C 0}-V_{0}\right) \cos \left(\omega_{0} t\right) \\
& +\left(-I_{L_{1} 0}-I_{L 0}\right) Z_{3} \sin \left(\omega_{0} t\right) \\
V_{0}= & \left(\frac{L_{1} V_{d}+L V_{s}}{L^{\prime}}\right) \\
i_{L}(t)= & -I_{0}+\left(I_{L 0}-I_{0}\right) \cos \left(\omega_{0} t\right) \\
& +\left(\frac{\left(V_{C 0}-V_{d}\right)}{Z_{1}}+\frac{\left(V_{s}-V_{d}\right)}{Z_{2}}\right) \sin \left(\omega_{0} t\right) \\
& +\frac{\left(V_{s}-V_{d}\right)}{Z_{2}}\left(\omega_{0} t\right)
\end{aligned}
$$

where for each mode

$$
\begin{aligned}
L^{\prime} & =L_{1}+L \\
\omega_{0} & =\sqrt{\frac{L^{\prime}}{L_{1} L C}}[\mathrm{r} / \mathrm{s}] \\
Z_{1} & =\sqrt{\frac{L L^{\prime}}{L_{1} C}} \\
Z_{2} & =L^{\prime} \sqrt{\frac{L^{\prime}}{L L_{1} C}} \\
Z_{3} & =\sqrt{\frac{L L_{1}}{L^{\prime} C}} \\
Z_{4} & =\sqrt{\frac{L_{1} L^{\prime}}{L C}} .
\end{aligned}
$$

Although the mathematical representation of the $L C L$ resonance is fairly complex, the design and operation of the converter is relatively straightforward in practice.

\section{Resonance Frequency Range}

With a given transformer and its leakage inductance, the resonance frequency of the $L C L$ tank can be calculated for a range of $C$ and $L$ components using (22). The contour for $\omega_{0}$ is shown in Figs. 4 and 5, where the leakage of the transformer $L_{1}$ is taken as $18 \mu \mathrm{H}$ [refer to Fig. 2(b)]. A listing of circuit parameters is found in Table I.

As can be seen in Fig. 5, for a given transformer leakage and desired switching frequency, there is a range of viable $L$ and $C$ component values. The switching frequency of the converter prototype was $25 \mathrm{kHz}$. The resulting $50 \mathrm{kHz} L C L$ resonance was accomplished with $C=1 \mu \mathrm{F}$, and $L=27 \mu \mathrm{H}$.

\section{Design Considerations}

In practice, once the input/output voltages and power levels of the converter are defined, a suitable transformer would be designed; size and weight are traded off with switching frequency and efficiency. The transformer constructed for the prototype converter utilized cut-toroidal ferrite cores. The

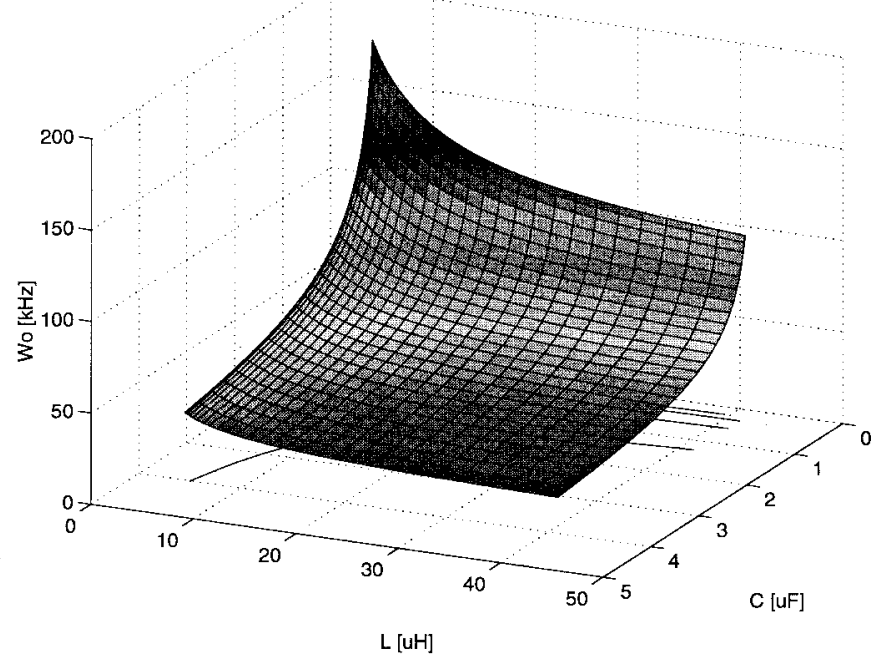

Fig. 4. $L C L$ resonant frequency three-dimensional contour over the $L-C$ range for $L_{1}=18 \mu \mathrm{H}$

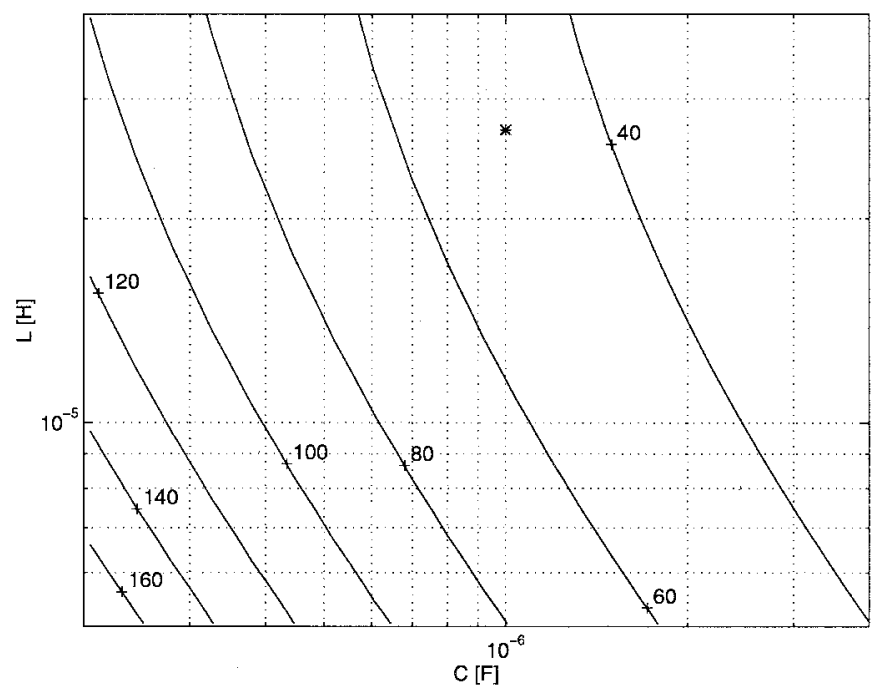

Fig. 5. $L C L$ constant resonant frequency lines $[\mathrm{kHz}]$ over the $L-C$ plane for $L_{1}=18 \mu \mathrm{H}$ : prototype point $(1 \mu \mathrm{F}, 27 \mu \mathrm{H}, 50 \mathrm{kHz})$ marked with $*$.

TABLE I

CONVERTER PARAMETERS

\begin{tabular}{l|c|c|c}
\hline Parameter & Symbol & Value & Units \\
\hline Input Voltage & $\mathrm{V}_{\mathbf{i}}$ & 12 & $\mathrm{~V}$ \\
\hline Nominal Output Voltage & $\mathrm{V}_{\mathrm{d}}$ & 235 & $\mathrm{~V}$ \\
\hline Nominal Output Power & $\mathrm{P}_{\mathrm{o}}$ & 1.8 & $\mathrm{~kW}$ \\
\hline Surge Output Power & $\mathrm{P}_{\mathrm{Os}}$ & 5 & $\mathrm{~kW}$ \\
\hline Lumped $\mathrm{R}_{\mathrm{ds}, \text { on }}$ & $\mathrm{R}_{\mathrm{ds}}$ & $\approx 1$ & $\mathrm{~m} \Omega$ \\
\hline Avalanche Diode Voltage & $\mathrm{V}_{\mathrm{Z}}$ & 60 & $\mathrm{~V}$ \\
\hline Resonant Capacitor & $\mathrm{C}$ & 1 & $\mu \mathrm{F}$ \\
\hline Resonant Inductor & $\mathrm{L}$ & 27 & $\mu \mathrm{H}$ \\
\hline Nominal Operating Frequency & $\mathrm{f}_{\mathrm{S}}$ & 25 & $\mathrm{kHz}$ \\
\hline
\end{tabular}

resultant airgap was found to be sufficient to prevent core saturation due to any slight volt-second unbalances between 


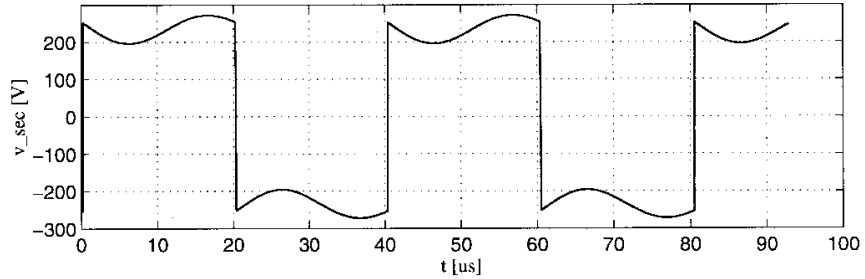

(a)

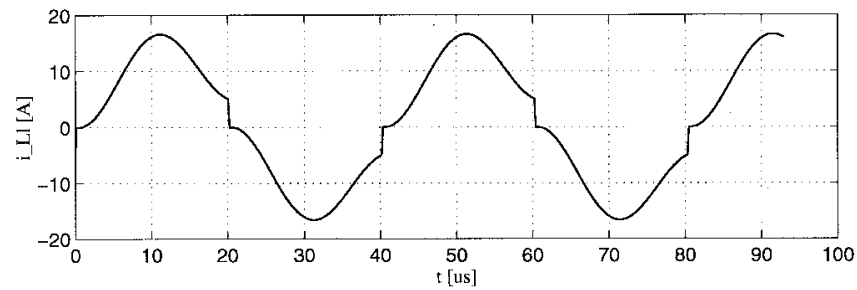

(b)

Fig. 6. Matlab simulation of (a) full-load transformer secondary voltage and (b) current.

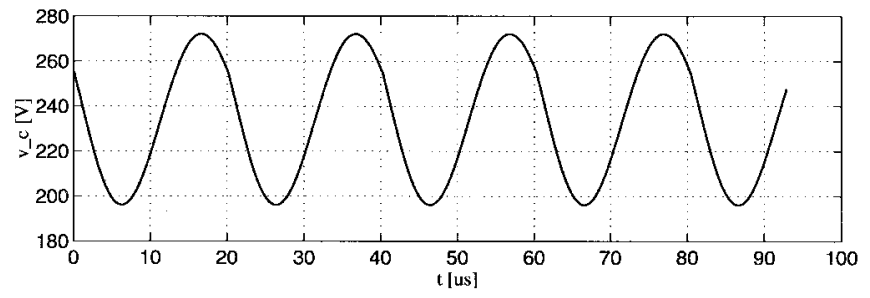

(a)

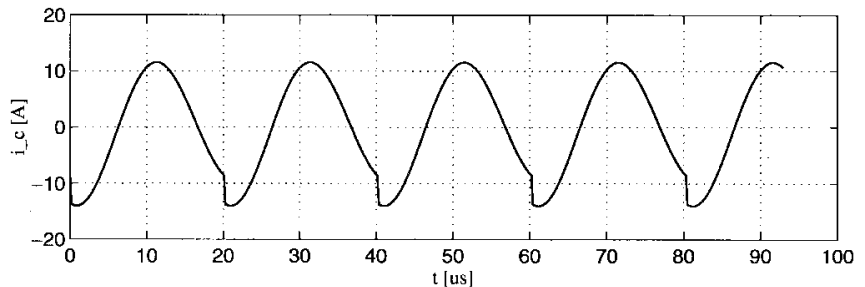

(b)

Fig. 7. Matlab simulation of (a) full-load resonant capacitor voltage and (b) current.

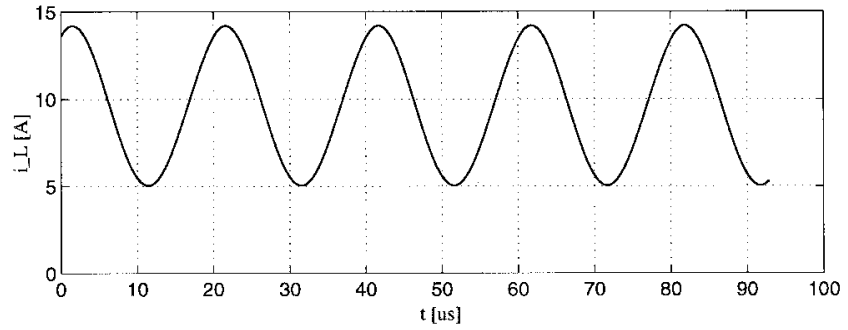

Fig. 8. Matlab simulation of resonant inductor current at full load.

the two primary windings. A separate balancing mechanism was not required.

The leakage inductance $L_{1}$ of the transformer is then determined and, for a desired switching frequency $f_{s}$, a range

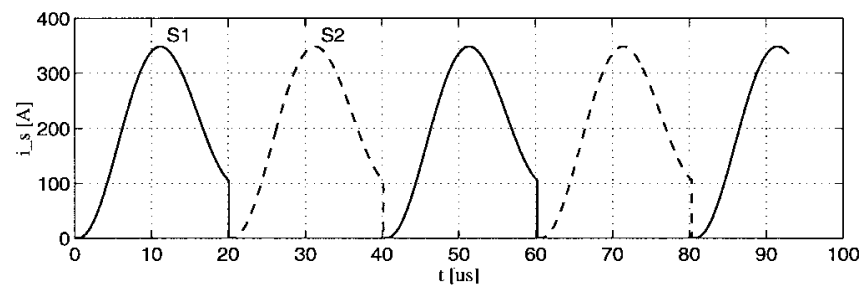

(a)

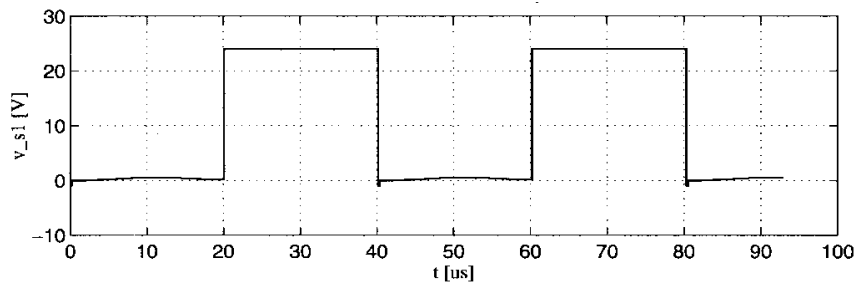

(b)

Fig. 9. Matlab simulation of (a) switch currents and (b) switch 1 voltage at full load

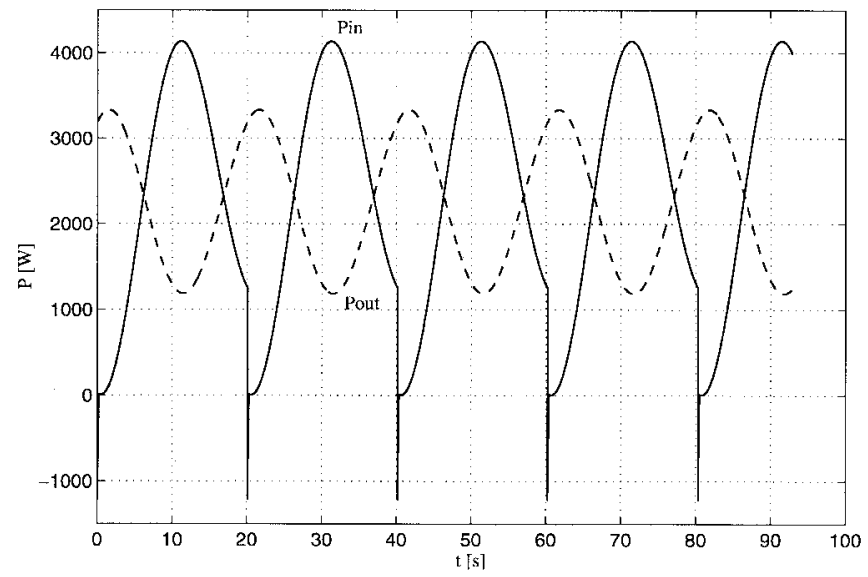

Fig. 10. Matlab simulation of full-load input and output power waveforms.

of $L$ and $C$ components can be found using (22), where $\omega_{0} \approx 2\left(2 \pi f_{s}\right)$. While it is difficult to extract exact design metrics from the mode equations listed previously, it can be observed qualitatively that larger values of $C$ will result in smaller deviations of $v_{c}$ and, thus, will reduce the voltage stress on the output rectifier diodes. This is traded off with higher ripple currents in both $C$ and $L$. Conversely, larger values of $L$ will reduce output ripple current at the cost of higher voltage deviations across $C$. In considering the depth of the resonance, the savings in turn-off loss obtained by minimizing the turn-off current must be weighed against higher conduction losses that will accompany higher peak resonance currents.

While any combination of $L$ and $C$ that satisfies (22) will work in theory, there is a limited selection of component values available. This will be particularly true for the resonant capacitor $C$. In general, circuit simulations should be used to evaluate which $L$ and $C$ values are optimal for each application. Resonant components with tight tolerances are not 


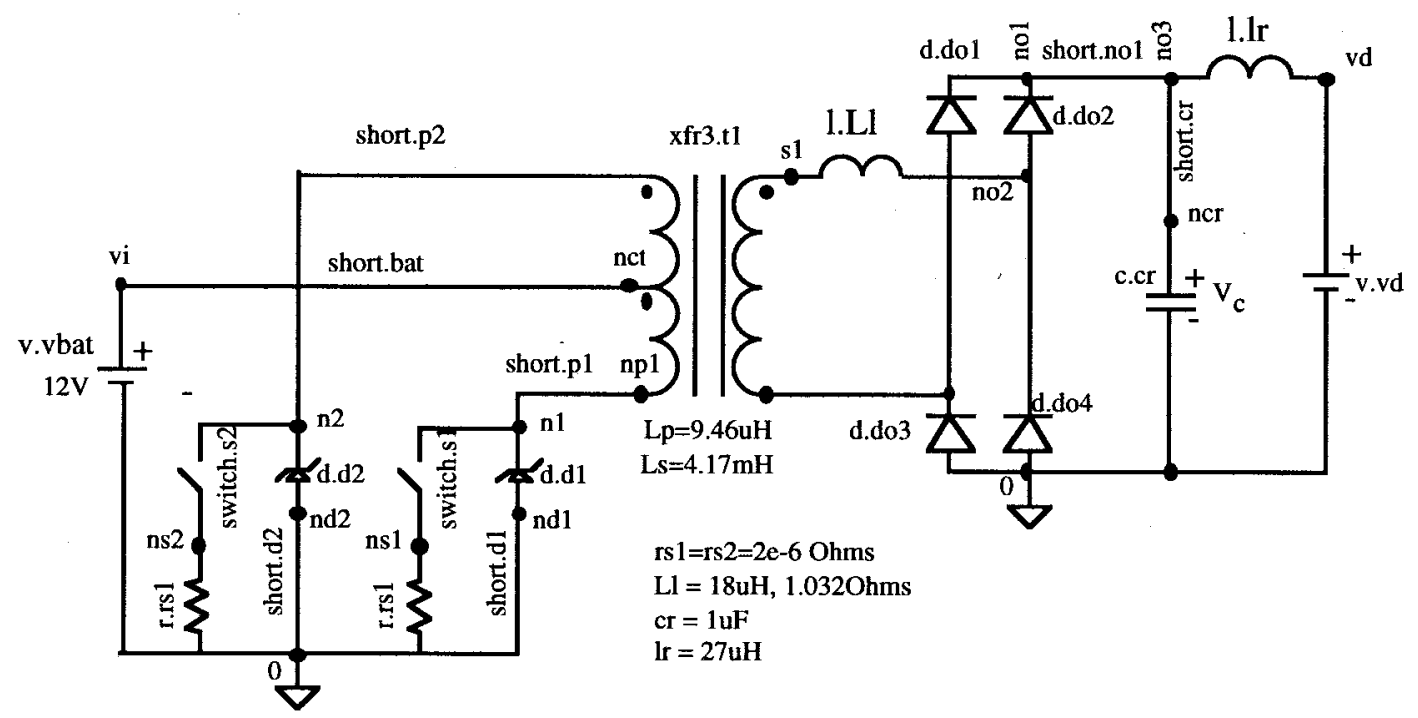

Fig. 11. Saber simulation circuit: lumped secondary model.

necessary, as the switching frequency of the converter can be easily "tuned" to match the resonance of the $L C L$ tank.

\section{CONVERTER Simulations}

Several time-based computer simulations were created to study the converter's operation under constant load conditions. The circuit parameters used in the simulations were set to match those of a prototype converter tested in the lab (see Section IV), and are listed in Table I. Refer to Fig. 2 for details on the transformer.

It should be noted that accurate computer simulations of the converter are invaluable, in that they allow access to circuit voltages and currents that are inaccessible with the actual hardware, i.e., the primary side currents of the converter where low-leakage packaging prohibits the use of a current probe.

\section{A. Matlab Simulations}

To simulate the fundamental operation of the converter, a time-based simulation was created in Matlab, where circuit operation was modeled via the differential equations for each of the four modes of operation. These differential equations include damping [lumped to the secondary side, see Fig. 2(b)] to allow convergence in the simulation. The differential equations for Mode 2 are found as:

$$
\begin{aligned}
& \dot{i}_{L_{1}}=\frac{1}{L_{1}}\left(V_{s}-i_{L_{1}} R_{L_{1}}-v_{C}\right) \\
& \dot{v}_{C}=\frac{1}{C}\left(i_{L_{1}}-i_{L}\right) .
\end{aligned}
$$

The differential equations for the other modes of operation are similarly formed. Note that, other than leakage inductance, the transformer is considered ideal, with $V_{s}= \pm\left(N V_{i}\right)$.

To evaluate the validity of (22), which does not account for damping, the $L C L$ resonance frequency was determined from the eigenvalues of the Mode 2 differential equations (27)-(29) as $\omega / 2 \pi=48.2 \mathrm{kHz}$. Comparing this to $\omega_{o} / 2 \pi=48.4 \mathrm{kHz}$ from (22), it can be concluded that (22) is sufficiently accurate for purposes of design.

Figs. 6-10 depict the simulated converter operation under full-load operation. In Fig. 6, note that the transformer voltage and current are in phase and transformer current is approximately sinusoidal, thus, transformer utilization is good. Note also that switching occurs at the minimum of the current oscillation, thus reducing the energy trapped in the primary leakage inductance. This has proven to be the most efficient operating point for the converter and is further discussed in Section III-B.

Figs. 7 and 8 depict the full-load waveforms of the resonant capacitor $C$ and inductor $L$. As can be seen, the capacitor voltage and inductor current oscillate about average dc offsets. Also, it can be seen that the resonant waveforms are relatively free of high-frequency harmonics that tend to incur higher losses. Fig. 9 depicts the voltage and current waveforms of the switches. Note that the off voltage imposed across the switches is twice that of the supply voltage, as is characteristic of push-pull converters.

Fig. 10 depicts the input and output power waveforms. It can be seen that the input power is discontinuous in nature, thus, the converter must include sufficient decoupling capacitance at the input to supply the resultant ripple current. The brief reverse-direction supply current "spike" produced during the switch transition Modes 1 and 3 is, thus, absorbed by these decoupling capacitors and not the supply. When primary-side leakage inductance is included in simulations, the amplitude of the reverse current is greatly reduced.

As will be seen, the simple models used in the Matlab simulation accurately reproduce the fundamental operation of the converter as observed in the laboratory. This acts to verify the analysis of Section II and lends credence to the converter design considerations, specifically, the resonance frequency given by (22). 


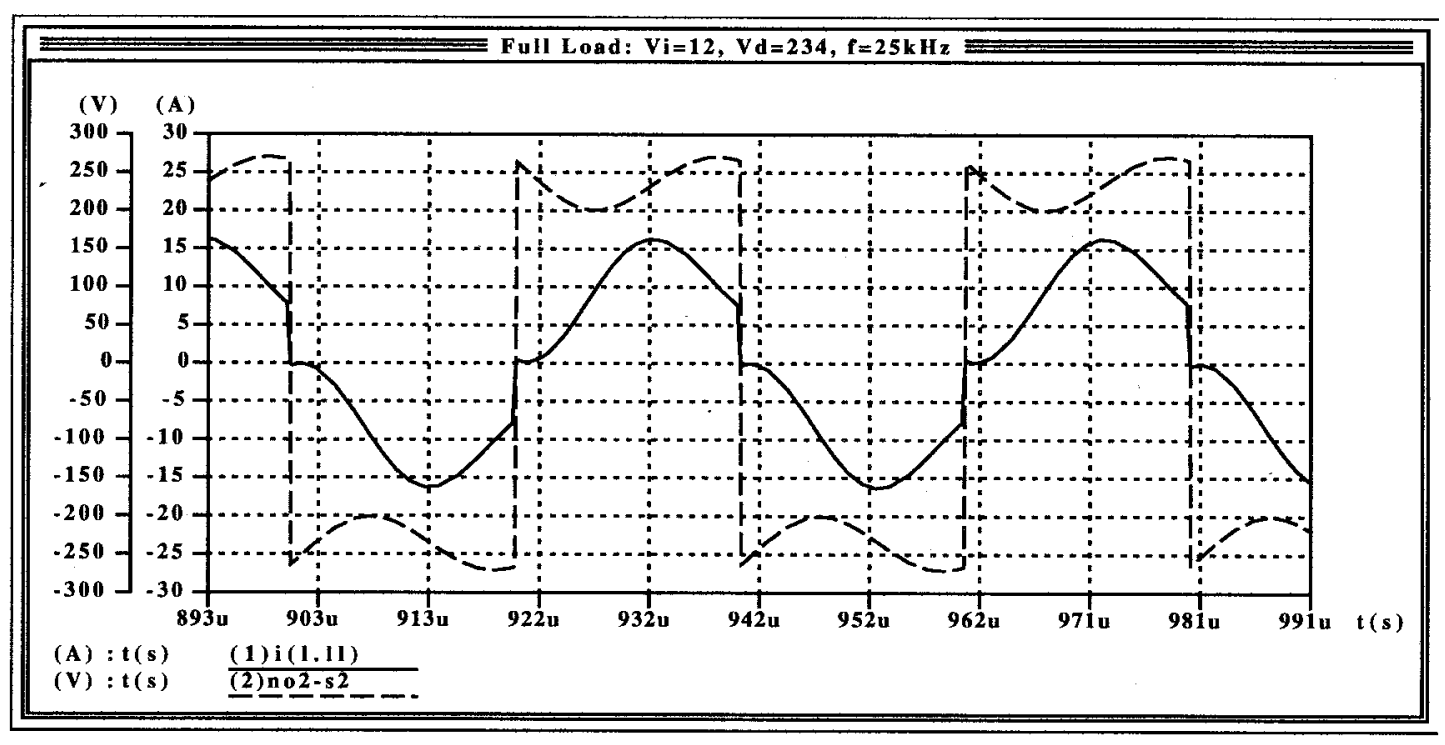

Fig. 12. Saber simulation results of transformer secondary voltage and current (full load).

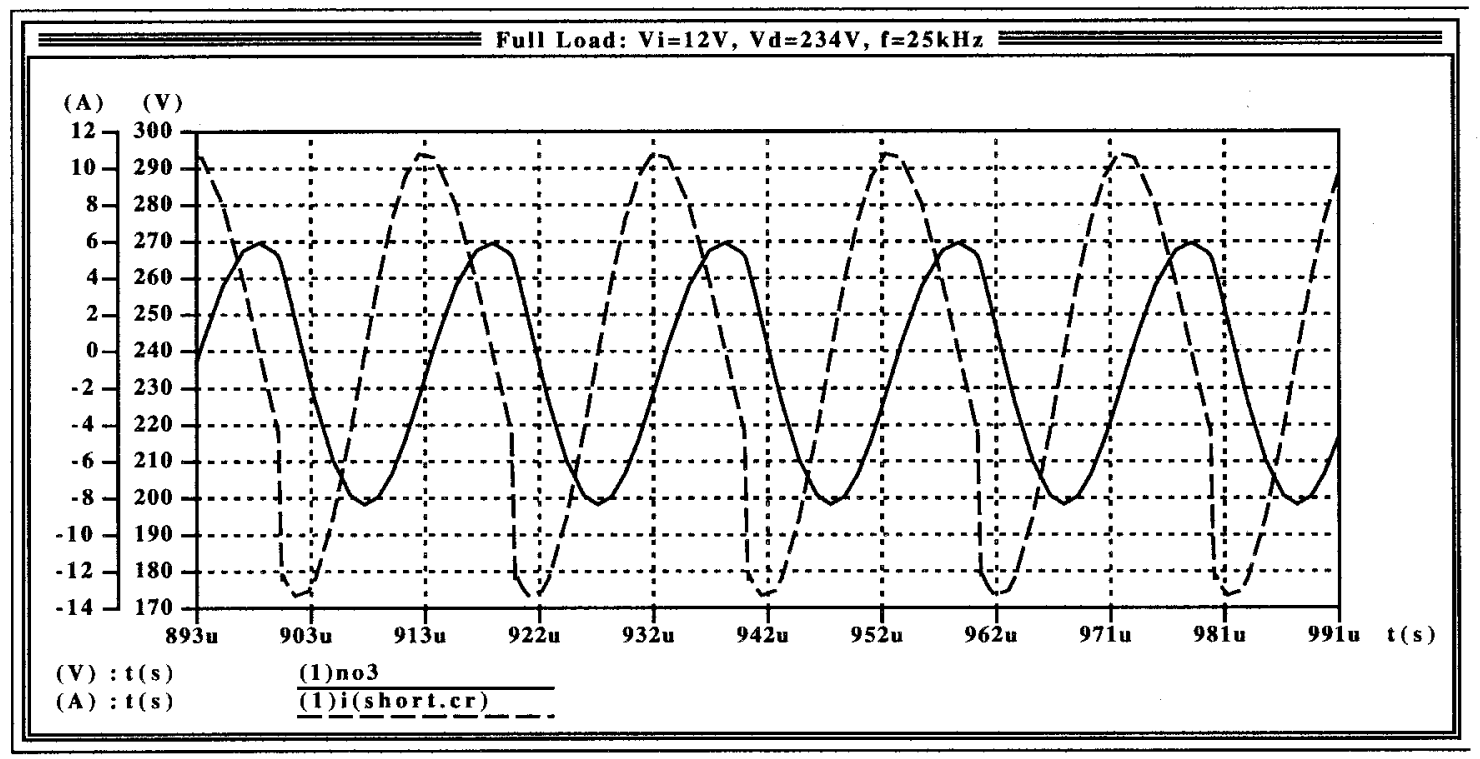

Fig. 13. Saber simulation of resonant capacitor voltage and current under full load.

\section{B. Saber Simulations}

To more accurately simulate the switching transitions and loss mechanisms of the circuit, circuit simulations were performed using the Saber simulation software. The circuit model used is depicted in Fig. 11.

While detailed Saber models for the MOSFET switches are available, it was found that these models significantly slowed the simulation and offered little additional insight into the operation of the converter. Thus, ideal switches with series resistance and an antiparallel zener diode were used to model the switches. These were found to be computationally efficient, while accurately reproducing results seen in laboratory tests. Note that all of the Saber simulations were done with an input voltage of $12 \mathrm{~V}$ and a switching frequency of $25 \mathrm{kHz}$, unless otherwise stated.
Fig. 12 below depicts the transformer secondary current and voltage under full-load conditions. Note the similarity with the Matlab results shown in Fig. 6. Figs. 13 and 14 depict the fullload waveforms of the resonant capacitor and inductor. Again, note the agreement with the Matlab results of Figs. 7 and 8.

To help understand the transition between modes, Fig. 15 depicts a close-up of the Mode $4 \rightarrow$ Mode $1 \rightarrow$ Mode 2 transition. Note in Fig. 15 that, when $S_{2}$ turns off, the current immediately transfers to the body diode $\left(D_{1}\right)$ of $S_{1}$. $S_{1}$ can now be gated on under ZVS conditions.

After the load current is driven toward zero, there is a long "tail" of diode current. This is the magnetizing current of the transformer being commutated. Once the diode current reaches zero, the current in $S 1$ begins to ramp up and the cycle continues. 


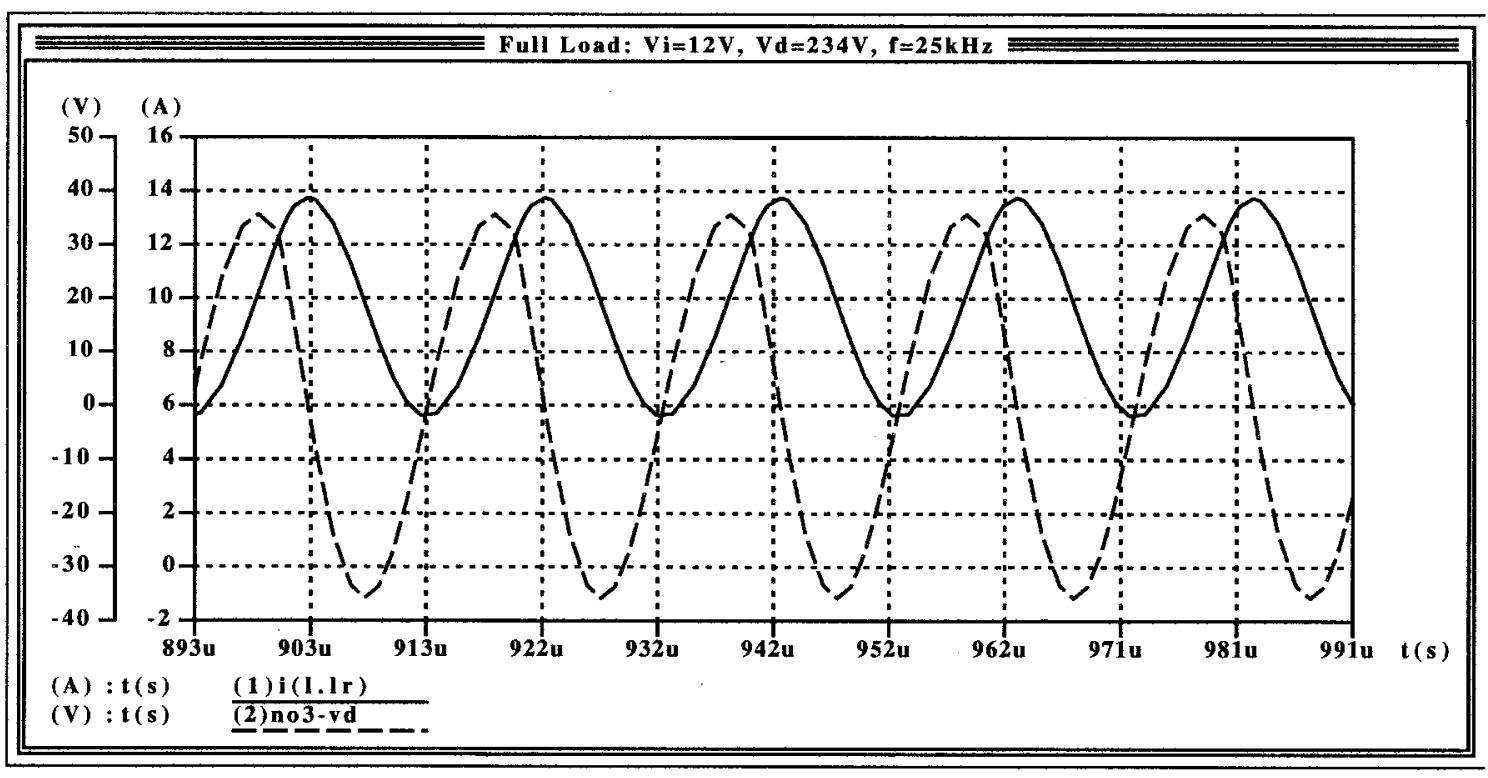

Fig. 14. Saber simulation of resonant inductor voltage and current under full load.

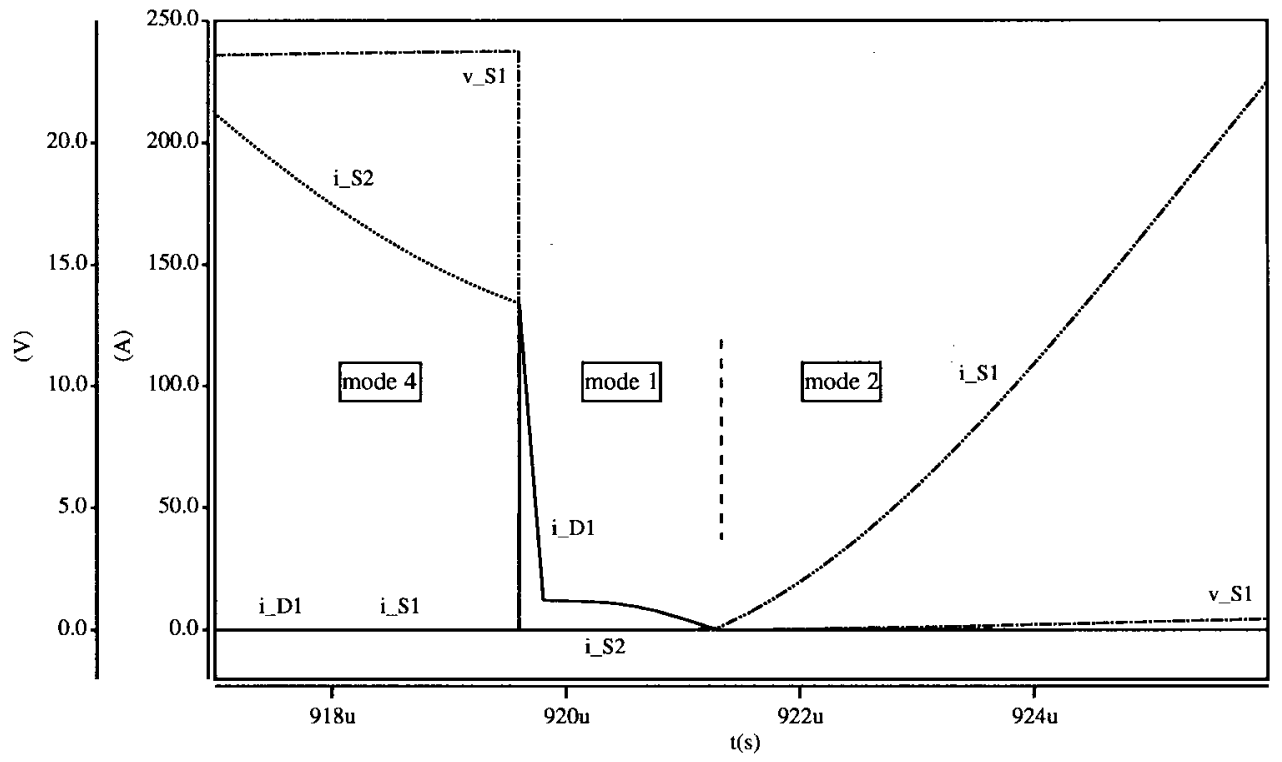

Fig. 15. Saber simulation of full-load mode transition: mode $4 \rightarrow$ mode $1 \rightarrow$ mode 2 .

Fig. 16 depicts the output voltage regulation of the converter. This represents a series of Saber simulations in which the converter was allowed to reach steady state for a range of output loading. The converter was found to operate as a dc voltage source with a finite output impedance: $Z_{\text {out }} \approx$ $1.6 \Omega$, or about 0.05 p.u. This open-loop voltage regulation is adequate for most intermediate voltage supply applications.

Fig. 17 depicts the efficiency of the converter over this same range of loading. Note that, from $1 / 4$ to $3 / 4$ load, the converter efficiency is at $95 \%$ or better. With such a low voltage source $(12 \mathrm{~V})$, this level of efficiency is as good or better than similar $\mathrm{dc}-\mathrm{dc}$ converters used in uninterruptible power supply (UPS) systems.
To demonstrate the effects of switching frequency on converter operation, Saber simulations were repeated for a range of switching frequencies. For these simulations, a fixed output load resistance of $30 \Omega$ was used. In addition, the transformer model was refined to include the primary-side leakage inductances, as depicted in Fig. 2(a). Figs. 18-21 depict the results.

Actual circuit operation differs slightly from that shown in Fig. 15. A more detailed analysis shows that the sharp triangular current pulse labeled $i D 1$ at the beginning of mode 1 (as MOSFET $S 2$ is turned off) would, in fact, be the current flowing in the avalanched body diode of $S 2$. The source (battery) current decreases from its mode 4 value toward zero 


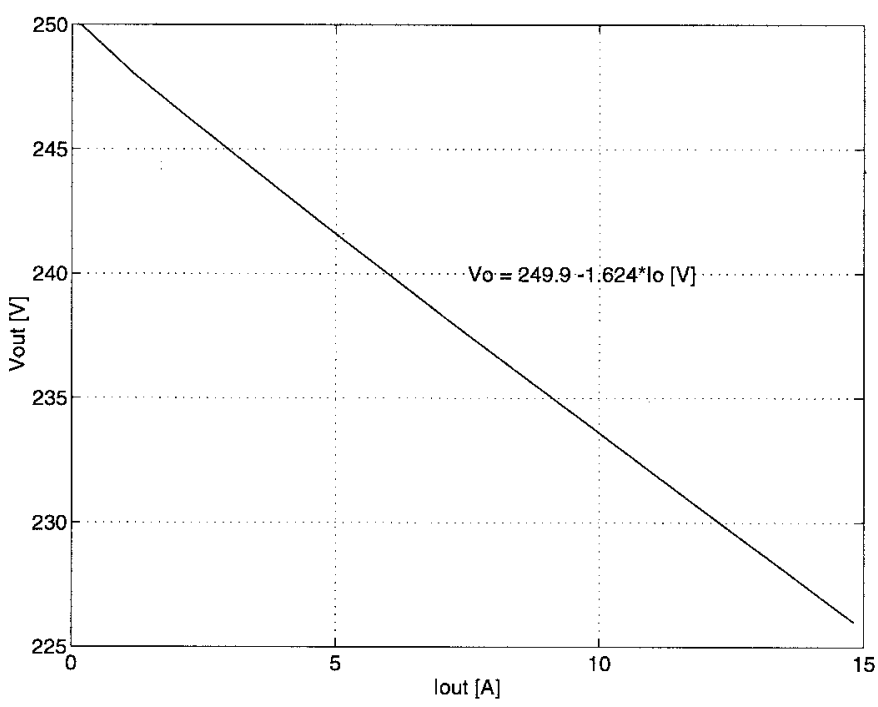

Fig. 16. Saber simulation of output voltage load regulation.

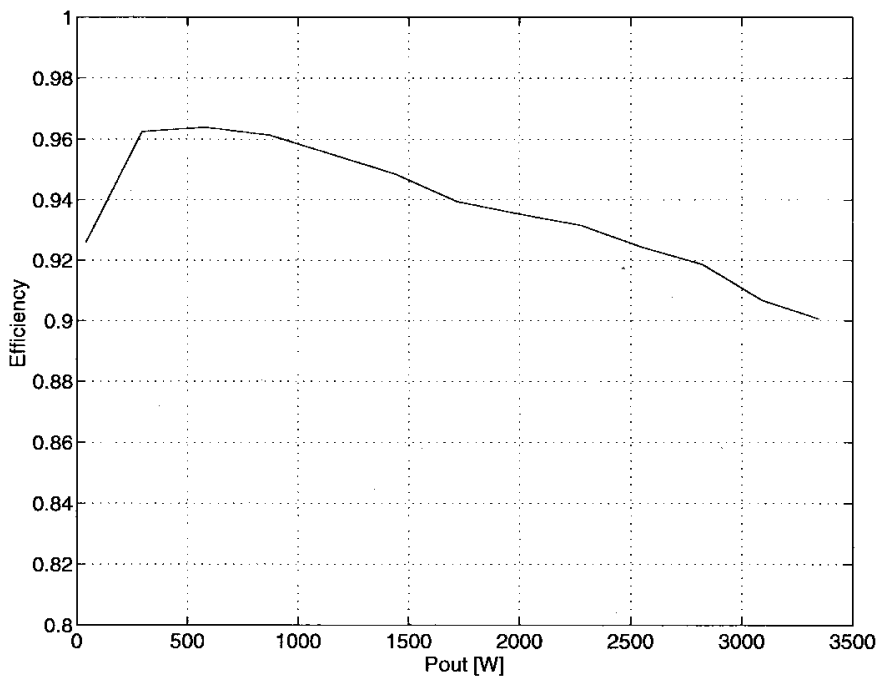

Fig. 17. Saber simulation of steady-state converter efficiency over load range.

along this same trajectory, and only the lower plateau of $i D 1$ in Fig. 15 actually flows in body diode $D 1$. Similarly, the body diode $D 1$ absorbs avalanche energy when $S 1$ is turned off at the end of mode 2 . All energy stored in the primary-side leakage inductance is dissipated in the avalanched MOSFET's.

Inspection of Figs. 18 and 19 shows that there is an optimum frequency tuning where the output voltage and efficiency reach a peak. This point directly corresponds to the minimum of avalanche diode power dissipation depicted in Figs. 20 and 21.

The sharp change in avalanche diode power loss can be understood by noting that the energy dissipated is always equal to the energy stored in the primary side leakage inductance $I^{2} L$ regardless of the avalanche voltage. Furthermore, the current is dramatically less at the tuned frequency. Thus, if the switching frequency is moved to a frequency which is not

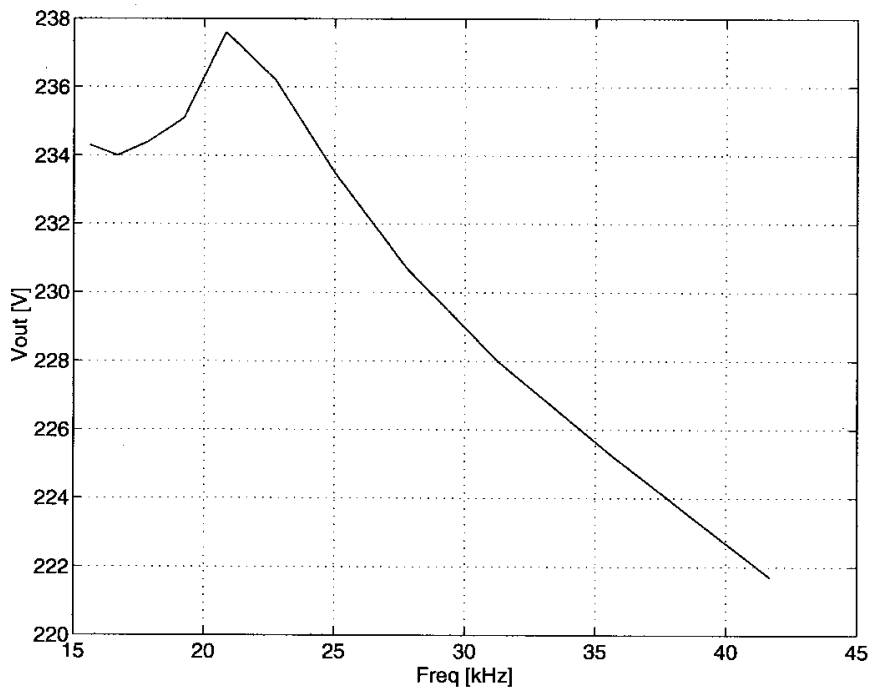

Fig. 18. Saber simulation of output voltage versus switching frequency $\left(R_{\text {load }}=30 \Omega, L_{l p}=20 \mathrm{nH}, f_{\text {resonance }} \approx 50 \mathrm{kHz}\right)$.

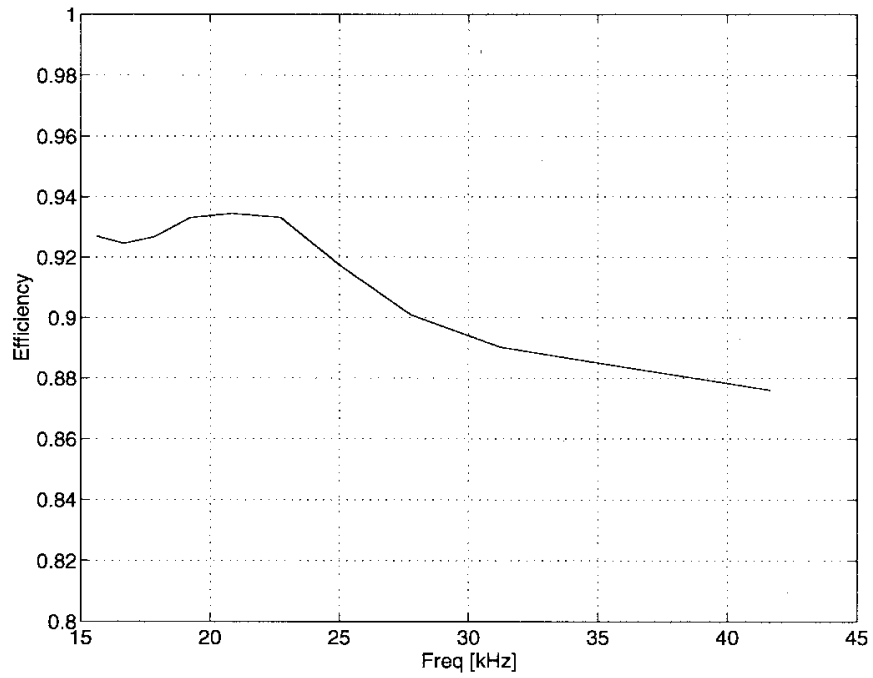

Fig. 19. Saber simulation of converter efficiency versus switching frequency $\left(R_{\text {load }}=30 \Omega, L_{l p}=20 \mathrm{nH}, f_{\text {resonance }} \approx 50 \mathrm{kHz}\right)$.

correctly tuned to the circuit, then the switch turn-off point is no longer at the minimum of the current resonance, and there is a corresponding dramatic increase in loss.

It will be shown in the next section that both the Matlab and Saber simulations accurately predict the fundamental operation of the $L C L$-resonant converter as seen in the laboratory. The detailed circuit-based nature of the Saber simulation allows for greater insight into the loss mechanisms of the design than either Matlab simulation or physical experiments.

\section{EXPERIMENTAL RESULTS}

A $12-\mathrm{V}$ input $2-\mathrm{kW}$ converter was built and tested in the lab. Figs. 22 and 23 show the transformer secondary voltage and current waveforms. 


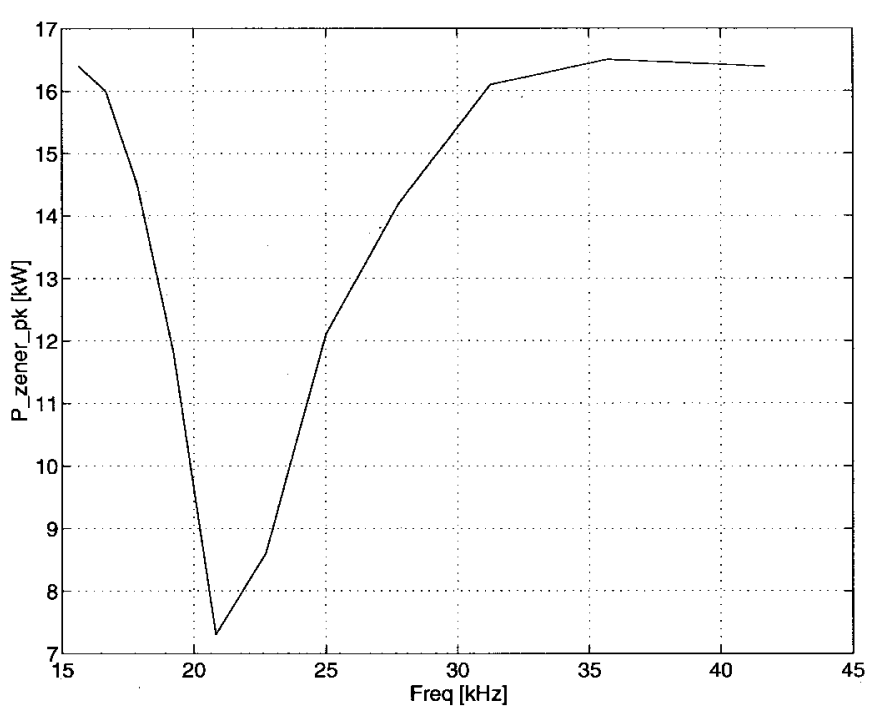

Fig. 20. Saber simulation of peak avalanche zener diode power versus switching frequency ( $R_{\text {load }}=30 \Omega, L_{l p}=20 \mathrm{nH}, V_{z}=60 \mathrm{~V}$, one switch).

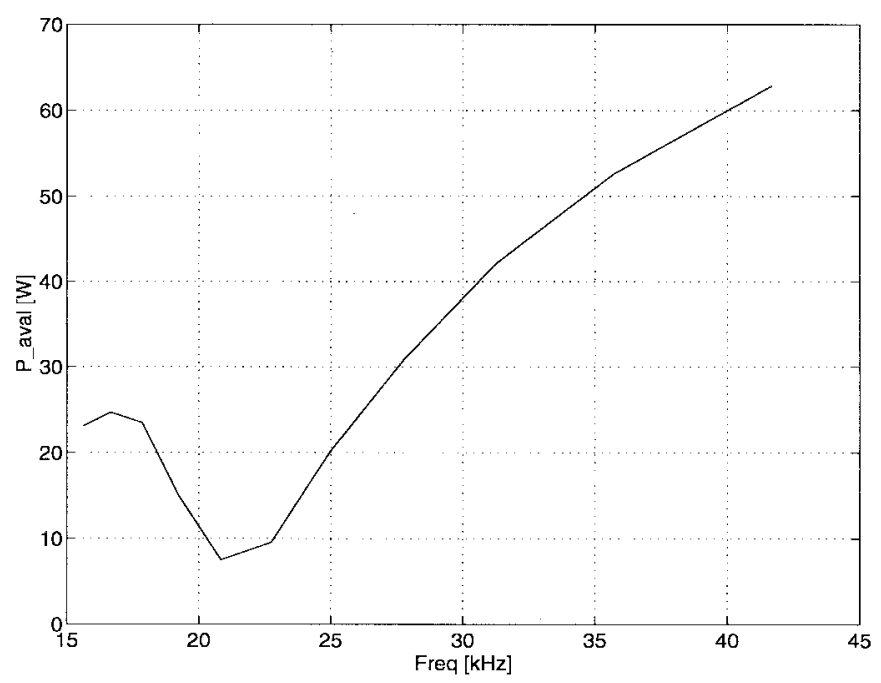

Fig. 21. Saber simulation of average avalanche zener diode power versus switching frequency $\left(R_{\text {load }}=30 \Omega, L_{l p}=20 \mathrm{nH}\right.$, one switch).

Comparing Fig. 22 to the computer simulation results (Figs. 6 and 12), it can be seen that the analysis and modeling of the converter accurately reproduces the operation of the converter in the laboratory. Note that the switching frequency of the converter was adjusted to obtain the maximum efficiency point.

In Fig. 23, it can be seen that the power flow exhibits a low "crest factor," thus, peak source currents are minimized. The converter has been successfully tested with a surge load of $5 \mathrm{~kW}$ for $1 \mathrm{~s}$. Table II lists the experimental results and compares them to the results of the Saber simulation. From Table II, it can be seen that the converter exhibits excellent full-load efficiency and that the Saber simulation results agree closely with the laboratory results.
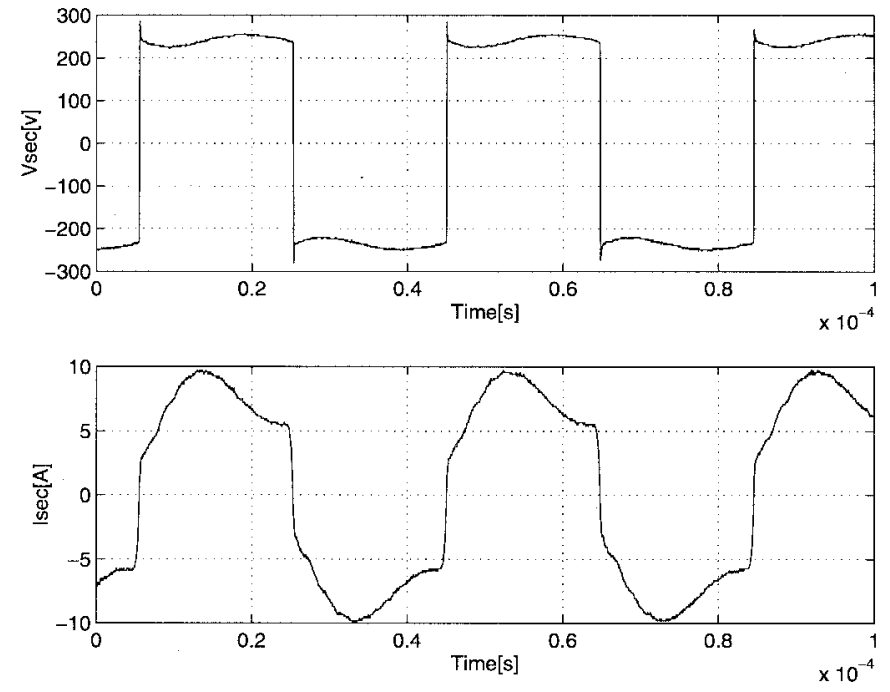

Fig. 22. Experimental transformer secondary voltage and current at full load $\left(1.7 \mathrm{~kW}, V_{\mathrm{in}}=12.0 \mathrm{~V}, V_{\text {out }}=235 \mathrm{~V}, F=25.3 \mathrm{kHz}\right)$.
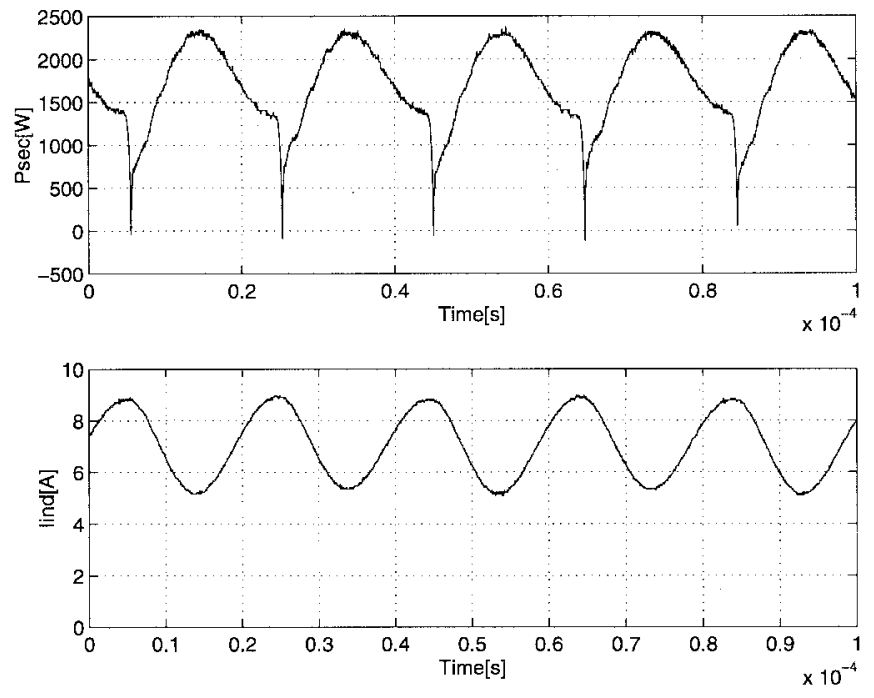

Fig. 23. Experimental transformer secondary power and output current at full load $\left(1.7 \mathrm{~kW}, V_{\text {in }}=12.0 \mathrm{~V}, V_{\text {out }}=235 \mathrm{~V}, F=25.3 \mathrm{kHz}\right)$.

TABLE II

Summary of Simulation AND EXPERIMENTAL RESUlTS

\begin{tabular}{l|c|c|c}
\hline Parameter & SaberTM Simulation & Experim. & Units \\
\hline Input Voltage, $\mathrm{V}_{\mathrm{i}}$ & 12 & 12 & $\mathrm{~V}$ \\
\hline Input Current, $\mathrm{I}_{\mathrm{i}}$ & 168 & 163 & $\mathrm{~A}$ \\
\hline Input Power, $\mathrm{P}_{\mathrm{i}}$ & 2.01 & 1.96 & $\mathrm{~kW}$ \\
\hline Output Voltage, $\mathrm{V}_{\mathrm{O}}$ & 237 & 234 & $\mathrm{~V}$ \\
\hline Output Current, $\mathrm{I}_{\mathrm{O}}$ & 7.9 & 7.8 & $\mathrm{~A}$ \\
\hline Input Power, $\mathrm{P}_{\mathrm{O}}$ & 1.87 & 1.82 & $\mathrm{~kW}$ \\
\hline Efficiency & 93.4 & 92.9 & $\%$ \\
\hline
\end{tabular}

\section{CONCLUSIONS}

The $L C L$-resonant topology presented is ideally suited for unregulated dc-dc conversion from a low-voltage high-current 
source, as it provides very high efficiency with simple operation.

- The circuit exhibits ZVS for the MOSFET switches and capacitively snubbed operation for the output rectifiers. The $L C L$ resonance reduces the energy trapped in the primary leakage inductance at turn-off, minimizing the avalanche energy dissipated in the MOSFET body diodes.

- The maximum efficiency operating point was found to occur with the switching frequency at nearly one-half the resonant tank natural frequency (subresonant operation). Resonant components can then be readily determined given the lumped leakage inductance of the transformer and the desired switching frequency.

- Laboratory tests have shown that this converter is easily "tuned" for maximum efficiency by adjusting the switching frequency for maximum output power. The converter has exhibited an input current-frequency product of 4.2 $\mathrm{A} \cdot \mathrm{MHz}$.

- Fundamental mode analysis and circuit simulations agree well with experimental results. Thus, converter operation is well characterized and predictable.

\section{REFERENCES}

[1] M. Shoyama and K. Harada, "Zero-voltage-switching realized by magnetizing current of transformer in push-pull DC-DC converter," in Proc. IEEE INTELEC'91, 1991, pp. 640-647.

[2] M. S. Rauls, D. W. Novotny, and D. M. Divan, "Design considerations for high frequency co-axial winding power transformers," in Conf. Rec. IEEE-IAS Annu. Meeting, 1991, pp. 946-952.

[3] M. S. Rauls, D. W. Novotny, D. M. Divan, R. R. Bacon, and R. W. Gascoigne, "Multi-turn high frequency co-axial winding power transformers," in Conf. Rec. IEEE-IAS Annu. Meeting, 1992, pp. 956-963.

[4] R. P. Severns, "Topologies for three-element resonant converters," IEEE Trans. Power Electron., vol. 7, pp. 89-98, Jan. 1992.

[5] _ "Generalized topologies for converters with reactive energy storage," in Conf. Rec. IEEE-IAS Annu. Meeting, 1989, pp. 1147-1151.

[6] I. Batarseh, "Resonant converter topologies with three and four energy storage elements," IEEE Trans. Power Electron., vol. 9, pp. 64-73, Jan. 1994.

[7] K. H. Liu and F. C. Lee, "Zero voltage switching technique in DC-DC converters," in Conf. Rec. IEEE PESC'86, 1986, pp. 58-70.

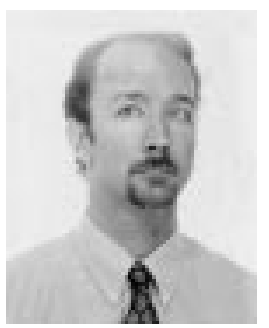

Michael J. Ryan received the B.S. degree from the University of Connecticut, Storrs, the M.E. degree from Rensselaer Polytechnic Institute, Troy, $\mathrm{NY}$, and the Ph.D. degree from the University of Wisconsin, Madison, in 1988, 1992, and 1997, respectively, all in electrical engineering.

He is currently engaged in post-doctoral research at the Institute for Power Electronics and Electric Drives, RWTH-Aachen, Aachen, Germany. He has had a wide range of industrial experience, with positions at General Electric, Hamilton Standard, and Otis Elevator. His work has included power electronic converters for brush and brushless PC motors, real-time microprocessor control and programming, path planning, kinematics and control for multiaxis winding machines, and soft-switching design of resonant inverters for ac traction motor applications. While at University of Wisconsin, Madison, he worked in the Wisconsin Electric Machines and Power Electronics Consortium Laboratories on projects including $\mathrm{dc}-\mathrm{dc}$ converters, variable speed generators, and UPS inverter control. In addition, he has worked with the school's Hybrid Electric Vehicle Group on vehicles that have won first-place titles at several national competitions.

Mr. Ryan is a member of the IEEE Industry Applications Society. He was a recipient of a Grainger Outstanding Power Engineering Student Award at the University of Wisconsin, Madison, in 1997.

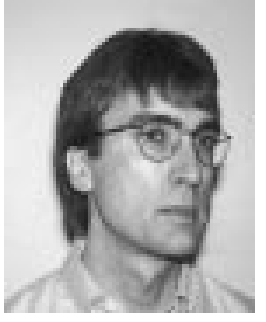

William E. Brumsickle received the B.S. degree in physics from the University of Washington, Seattle, and the M.S. degree in electrical engineering and the Ph.D. degree from the University of Wisconsin, Madison, in 1982, 1995, and 1997, respectively.

From 1986 to 1992, he was with Enerpo Inc.

Goleta, CA, mainly working as an Applications Engineer for thyristor phase control applications. Since 1993, he has been a Research Assistant in the Wisconsin Electric Machines and Power Electronics Consortium Laboratories, University of Wisconsin, Madison, where his work has included development of a high-efficiency dc-dc converter for battery-powered stand-alone and UPS inverters, investigations of high-power inverter and UPS topologies, and analysis of power-electronicbuilding-block (PEBB)-based systems. His present research focus is highvoltage IGBT-based soft-switching inverters for multimegawatt systems.

Mr. Brumsickle is a member of the IEEE Industry Applications and IEEE Power Electronics Societies. He was a recipient of a Grainger Outstanding Power Engineering Student Award at the University of Wisconsin, Madison, in 1997.

Deepak M. Divan (S'78-M'78-SM'91-F'98), for a photograph and biography, see p. 250 of the March/April 1998 issue of this TRANSACTIONS.

Robert D. Lorenz (S'83-M'84-SM'91-F'98), for a photograph and biography, see p. 247 of the March/April 1998 issue of this TRANSACTIONS. 